\title{
INDICADORES DE ESTRESSE SALINO EM ABACAXIZEIRO CULTIVADO NA AUSÊNCIA E PRESENÇA DE FITORREGULADORES ${ }^{1}$
}

\author{
YURI LIMA MELO², ISABELE ARAGÃO GOMES ${ }^{3}$, CIBELLEY VANÚCIA SANTANA DANTAS ${ }^{3}$, \\ LUCILA KARLA FÉLIX DE BRITO ${ }^{4}$, MÔNICA DANIELLY DE MELLO OLIVEIRA ${ }^{5}$, \\ CRISTIANE ELIZABETH COSTA DE MACÊDO ${ }^{6}$
}

RESUMO - O objetivo do presente estudo foi avaliar o efeito de diferentes concentrações de $\mathrm{NaCl}$ nas fases de multiplicação e enraizamento in vitro do abacaxizeiro cultivar MD Gold. Brotos de abacaxizeiro foram inoculados em meio MS, na ausência e presença dos fitorreguladores ácido naftalenoacético (ANA) e 6-benzilaminopurina (BAP) e também de diferentes concentrações de $\mathrm{NaCl}$ (Controle - 0; 50; 100 e 150 $\mathrm{mM}$ ). Mensalmente, os brotos foram subcultivados e foram analisados altura média, número de folhas vivas e mortas, taxas de brotação e enraizamento. Durante a multiplicação e na ausência de ANA e BAP, o NaCl provocou significativa redução no crescimento e desenvolvimento de brotos de abacaxizeiro, expresso pela altura e pelo número de folhas, nas doses mais elevadas, contrariamente, na presença dos fitorreguladores. Durante os 60 dias iniciais, ocorreu aumento na produção de folhas. Contudo, aos 90 dias, observou-se decréscimo na média de folhas vivas nos brotos tratados com sal. O cultivo in vitro de abacaxizeiro em presença de sal é mais eficiente na presença de ANA e BAP, garantindo a manutenção do crescimento, aumentando o número de folhas, produzindo novas gemas e acelerando o processo de enraizamento.

Termos para indexação: Ananas comosus, estresse salino, fitorreguladores, cultivo in vitro.

\section{SALINITY INDICATORS IN PINEAPPLE GROWN IN THE ABSENCE AND PRESENCE OF GROWTH REGULATORS}

\begin{abstract}
To assess the effects of salt on the pineapple MD Gold during the multiplication and rooting phases in vitro, this study evaluated its performance in different concentrations of $\mathrm{NaCl}$ in the absence or presence of growth regulators. Pineapple shoots were inoculated on MS solution in the absence and presence of the growth regulators naphthaleneacetic acid (NAA) and 6-benzlaminopurine (BAP) and different concentrations of $\mathrm{NaCl}$ (Control - 0, 50, 100 and $150 \mathrm{mM}$ ). Monthly, shoots were subcultured and it was analyzed height, number of alive and dead leaves, and the rates of sprouting and rooting. During the multiplication in the absence of NAA and $\mathrm{BAP}$, the $\mathrm{NaCl}$ treatments caused significant reduction in growth and development of pineapple shootings, expressed by the height and number of leaves, in the highest dose, which was not observed in the presence of growth regulators. During the first 60 days, an increase in leaf production occurred. However, after 90 days, there was a decrease in average living leaves in the shoots treated with salt. The in vitro cultivation of pineapple in the presence of salt is more efficient in the presence of NAA and BAP, ensuring continued growth, increasing the number of leaves, producing new buds and accelerating the process of rooting.
\end{abstract}

Index terms: Ananas comosus, salt stress, plant growth regulators, in vitro culture.

\footnotetext{
${ }^{1}$ (Trabalho 186-10). Recebido em: 04-08-2010. Aceito para publicação em: 21-12-2010. Apoio Financeiro: EMPARN-EMBRAPA (OEPAS).

${ }^{2}$ Mestrando do Programa de Pós-Graduação em Fitotecnia/DCV/UFERSA, Mossoró - RN. Bolsista CAPES. E-mail: yurl_melo@yahoo.com.br

${ }^{3}$ Graduada em Ciências Biológicas/CBC/UFRN, Natal - RN. E-mails: isabele_ag@yahoo.com.br; cibelley_rn@hotmal.com

${ }^{4}$ Mestre em Ciências Biológicas/CBC/UFRN, Natal - RN. E-mail:lflbrito@gmail.com

${ }^{5}$ Doutoranda do Programa de Pós-Graduação em Fitotecnia /DCV/UFERSA, Mossoró - RN. E-mail:monicadmportella@hotmail.com ${ }^{6}$ Prof ${ }^{\mathrm{a}}$. Dra. do DBG/CBC/UFRN, Natal - RN.E-mail: cristianemacedo@ufrnet.br
} 


\section{INTRODUÇÃO}

A cultivar de abacaxi MD Gold é um duplo híbrido descendente da Smooth Cayene e vem atraindo interesse tanto do mercado interno quanto do externo, devido a seus frutos apresentarem alto conteúdo de açúcar ( ${ }^{\circ}$ brix 16-18), formato regular, coroa pequena-média e ainda folhas lisas (CHAN et al., 2002; BIONOVA, 2009).

O Estado do Rio Grande do Norte destaca-se por contribuir com aproximadamente $5 \%$ da produção nacional de abacaxi (IBGE, 2008), entretanto ainda não produz a cultivar MD Gold. A produção do Estado é comprometida pela deficiência hídrica e salinização dos solos, agravadas pelo manejo agrícola e qualidade da água inadequados (CARMO et al., 2003), além da alta taxa de evapotranspiração e baixa pluviosidade (BRITO et al., 2007).

A salinidade é um dos estresses abióticos que mais restringe a produção agrícola, pois inibe o crescimento e a produtividade das culturas, agindo osmótica e ionicamente (MACÊDO et al., 2005), dificultando a absorção de água por parte das raízes e causando toxicidade as plantas (BRILHANTE et al., 2007).

Assim, a identificação e seleção de culturas e cultivares resistentes à salinidade é de fundamental importância para serem utilizados em programas de melhoramento genético. O gerenciamento de técnicas adequadas para a criação de plantas geneticamente modificadas são ferramentas que aperfeiçoam a eficiência do uso de recursos por parte das plantas (CHAVES et al., 2009).

Dessa forma, técnicas de cultura de tecidos vegetais vêm sendo largamente aplicadas, não só pela possibilidade de se obterem plantas mais resistentes a fatores de estresses bióticos e abióticos, mas também pela rápida propagação clonal in vitro de plantas de novas variedades (MACÊDO, 2003). A partir de técnicas de cultura de tecidos vegetais, através de variantes somaclonais, associados a uma pressão de seleção, podem-se obter genótipos resistentes a fatores adversos, dentre os quais a salinidade, largamente utilizada no melhoramento de diferentes espécies (LUTTS et al., 2004).

Trabalhos utilizando diferentes doses de $\mathrm{NaCl}$ para uma posterior seleção in vitro, em abacaxizeiro, mostraram que a presença do sal afetou diferentes indicadores de crescimento expressos pela produção de brotos, altura e número de folhas (BRITO et al., 2007; MEDEIROS et al., 2001). Tais resultados também foram observados em outras espécies, como a bananeira, cuja adição de $\mathrm{NaCl}$ ao meio de cultura afetou a multiplicação in vitro, e que o aumento da concentração do sal é proporcional à diminuição do número de brotos produzidos (MACÊDO et al., 2005). Adicionalmente, o uso de fitorreguladores, como o 6-benzilaminopurina (BAP), e o ácido naftalenoacético (ANA), na micropropagação, é fundamental para obtenção de um número suficiente de brotos de abacaxizeiro com parte aérea mais alongada e que permita sua melhor individualização e enraizamento (MACÊDO et al., 2003). De acordo com Medeiros et al. (2001), a associação de concentrações de ANA e BAP no meio de cultura favorece tanto a multiplicação como o enraizamento de abacaxizeiro.

Como na micropropagação se desconhece a dose resposta ao $\mathrm{NaCl}$ e a necessidade ou não de utilização de hormônios vegetais na cultivar MD Gold, o objetivo do presente estudo foi avaliar o efeito de diferentes concentrações de $\mathrm{NaCl}$ nas fases de multiplicação e enraizamento em abacaxizeiro da cultivar MD Gold durante o seu cultivo in vitro, tanto na ausência como na presença dos fitorreguladores ANA e BAP, usando, como indicadores de estresse, parâmetros métricos de crescimento representados pela altura, número de folhas e taxas de brotação e enraizamento.

\section{MATERIAL E MÉTODOS}

Brotos de abacaxizeiro da cultivar MD Gold obtidos a partir de gemas, medindo entre 7 e 10 centímetros, foram utilizados neste trabalho. Durante a multiplicação, os brotos foram inoculados em meio de cultura básico constituído pelos sais e vitaminas MS (MURASHIGE; SKOOG, 1962) e suplementado com $30 \mathrm{~g} \mathrm{~L}^{-1}$ de sacarose e $100 \mathrm{mg} \mathrm{L}^{-1}$ de mio-inositol, na ausência (controle) e na presença de 3 diferentes concentrações de $\mathrm{NaCl}(50 ; 100$ e $150 \mathrm{mM})$, bem como na ausência e em presença dos fitorreguladores ANA e BAP, na proporção de 1:0,5 $\mathrm{mg} \mathrm{L}^{-1}$, respectivamente. $\mathrm{O} \mathrm{pH}$ dos meios foi ajustado para 5,7 antes da autoclavagem, e, em seguida, os meios foram distribuídos igualmente em frascos $(25 \mathrm{~mL}$ de meio/ frasco de $300 \mathrm{~mL}$ ), em condições assépticas, na capela de fluxo laminar. Os frascos contendo os brotos foram mantidos em sala de crescimento, com temperatura de $25 \pm 5{ }^{\circ} \mathrm{C}$, intensidade luminosa de $30 \mu \mathrm{mol} \mathrm{m} \mathrm{m}^{-2} \mathrm{~s}^{-1}$ e fotoperíodo de 12/12 horas (claro/ escuro), durante 90 dias. A cada 30 dias, os brotos foram subcultivados nos respectivos meios de cultura frescos. Mensalmente, durante 90 dias, foram analisados indicadores de crescimento representados pela altura média dos brotos, número de folhas vivas e mortas, número médio de brotos formados por broto regenerado (total de brotos formados/número de 
propágulos que formaram brotos) e taxa de brotação [(broto formado/broto inoculado) x 100].

Ao final dos 90 dias de multiplicação, os brotos foram transferidos para o meio de enraizamento, permanecendo por mais 90 dias nas mesmas condições de cultivo. No enraizamento, os brotos iniciais, dos diferentes tratamentos oriundos da multiplicação, foram transferidos para o meio de cultura básico constituído pelos sais e vitaminas MS diluídos pela metade na ausência de $\mathrm{NaCl}$, suplementado com $15 \mathrm{~g} \mathrm{~L}^{-1}$ de sacarose e $50 \mathrm{mg} \mathrm{L}^{-1}$ de mioinositol, acrescido com $0,1 \mathrm{mg} \mathrm{L}^{-1}$ de ANA para indução de formação de radículas. Os frascos contendo os brotos e/ou plântulas (brotos que enraizaram) foram mantidos em sala de crescimento, nas mesmas condições descritas acima, durante a etapa de multiplicação, durante 90 dias. A cada 30 dias, os brotos e as plântulas foram subcultivados nos respectivos meios de cultura frescos e computadas suas taxas de enraizamento [(formação de raiz/broto inoculado) $\mathrm{x} 100]$.

$\mathrm{O}$ delineamento experimental, durante a multiplicação, foi inteiramente casualizado, usando esquema fatorial $4 \times 2,4$ (quatro) tratamentos com sal (controle + três doses de $\mathrm{NaCl}$ ) e 2 (dois) tratamentos (ausência e presença de fitorreguladores), perfazendo 8 (oito) tratamentos, sendo 5 (cinco) repetições por tratamento e inoculando-se um broto por frasco. O mesmo delineamento experimental foi seguido durante o enraizamento, utilizando os brotos oriundos da multiplicação. Assim, do material vegetal, 20 brotos foram destinados ao tratamento na ausência de fitorreguladores, e 20 brotos foram destinados ao tratamento na presença de fitorreguladores, ambos na ausência (Controle) e em presença de 3 (três) concentrações de $\mathrm{NaCl}(50 ; 100$ e $150 \mathrm{mM})$.

Os dados coletados foram submetidos à análise de variância. O teste de Tukey foi realizado a $5 \%$ de probabilidade, sempre que o teste $F$ verificou diferenças significativas entre os tratamentos.

\section{RESULTADOS E DISCUSSÃO}

Na fase de multiplicação de brotos da cultivar MD Gold e na ausência de ANA e BAP, a presença de $\mathrm{NaCl}$ no meio de cultura provocou significativa redução no crescimento e no desenvolvimento de abacaxizeiro, expresso pelo número médio de folhas vivas em todas as concentrações de $\mathrm{NaCl}$ e pela altura, nas doses mais elevadas (100 e $150 \mathrm{mM}$ ) (Tabela 1). Resultados semelhantes foram observados em trabalhos com a mesma cultivar de abacaxizeiro submetidos a diferentes concentrações de $\mathrm{NaCl}$ (VIEIRA et al., 2008) e com as cultivares Pérola e Smooth Cayenne (BARROSO et al., 2003).
A elevada concentração de íons no solo, principalmente $\mathrm{Na}^{+}$e $\mathrm{Cl}^{-}$, pode causar a disrupção na homeostase do potencial de água e o desbalanço iônico na interface solo-planta, promovendo a toxicidade no vegetal. Consequentemente, isso pode afetar o crescimento e a produção de fitomassa (ASCH et al., 2000). Dessa forma os processos de crescimento são particularmente sensíveis ao efeito dos sais e da pressão osmótica, tornando análises de crescimento, como altura média, número de folhas, brotos formados e taxa de enraizamento, bons critérios para a avaliação da severidade do estresse e da capacidade da planta de superá-lo (ESTEVES; SUZUKI, 2008).

Observou-se retardo no desenvolvimento dos brotos, devendo-se, possivelmente, a um efeito iônico e/ou osmótico provocado pelo sal. Os mesmos efeitos foram observados em soja (MORAES; MENEZES, 2003). O sal retém a água na solução de forma que o aumento gradativo da concentração de cloreto de sódio torna a água cada vez menos disponível para a planta (ZHU, 2001). A redução no crescimento deve-se, provavelmente, a uma diminuição na divisão e alongamento celular (XIONG; ZHU, 2001). Segundo Macêdo et al. (2005), que também obtiveram resultados semelhantes com bananeira, em alta salinidade, a expansão celular pode ser reduzida pelo acúmulo de sais na parede celular, reduzindo o turgor e, consequentemente, o crescimento. De acordo com Cruz et al. (2003), o acúmulo de íons $\mathrm{Na}^{+}$dá-se preferencialmente nas folhas mais velhas, provavelmente por ser um mecanismo adaptativo para proteger os ápices e as folhas fisiologicamente mais ativas. A diminuição da produção de folhas vivas pode estar relacionada não só ao efeito do sal, mas também à ausência dos fitorreguladores; tal redução pode ser devido à incapacidade de a planta produzir novas folhas mais rapidamente que a senescência (MUSCOLO et al., 2003), além da morte das folhas mais velhas por necrose de seus tecidos.

Curiosamente, na presença de ANA e BAP, o sal não interferiu no crescimento dos brotos, expresso pela altura média (Tabela 1). Provavelmente, o efeito do sal foi modulado pela presença dos fitorreguladores. Sabe-se que as auxinas e as citocininas regulam vários processos de desenvolvimento nas plantas, como, por exemplo, a formação de raízes, caules, folhas, apresentando multiplicidade de efeitos, dependendo do local de ação, do estágio de desenvolvimento da planta, da concentração e da sensibilidade celular (MAIOCHI et al., 2007). Em todos os tratamentos salinos na presença de ANA e $\mathrm{BAP}$, durante os 60 primeiros dias, houve aumento na produção de folhas, sendo maior no grupo-controle (Tabela 1). Os fitorreguladores que, no meio de 
cultura, favorecem a multiplicação celular, podem estar associados ao aumento do número de folhas. Contudo, aos 90 dias, observa-se decréscimo na média de folhas vivas nos brotos tratados com sal. Tal diminuição foi diretamente proporcional ao aumento na média de folhas mortas causado, provavelmente, pelo acúmulo de íons $\mathrm{Na}^{+}$intracelular.

$\mathrm{Na}$ ausência dos fitorreguladores, os brotos multiplicaram-se apenas após 90 dias de cultivo (T3) nos grupos-controle e no tratado com $50 \mathrm{mM}$ de sal, não havendo formação de novos brotos nos demais tratamentos com $\mathrm{NaCl}$ (Figura 1 -A). Entretanto, em presença de ANA e BAP, o grupo-controle e os demais tratamentos contendo diferentes concentrações de $\mathrm{NaCl}$ apresentaram formações de novos brotos já nos primeiros 30 dias de cultivo (T1), exceto em 150 $\mathrm{mM}$ de $\mathrm{NaCl}$ (Figura 1 - B). Após 90 dias, o controle apresentou maior número médio de brotos formados por broto inoculado, tanto na ausência (Controle $0,4 ; 50 \mathrm{mM}-0,2 ; 100 \mathrm{mM}-0 ; 150 \mathrm{mM}-0)$ como na presença dos fitorreguladores (Controle - 10,6; $50 \mathrm{mM}-5 ; 100 \mathrm{mM}-3,2 ; 150 \mathrm{mM}-1,8)$. Esse número diminuiu com o aumento da concentração de $\mathrm{NaCl}$ no meio de cultura.

Essa redução do número de propágulos, na ausência e presença de ANA e BAP, pode estar relacionada a fenômenos associados ao estresse salino, como retardo no aparecimento e atrofiamento das gemas além de alterações na divisão e expansão celular (XIONG; ZHU, 2001). A presença dos fitorreguladores ANA e BAP interfere ativamente, minimizando o efeito do sal na produção de novas gemas. O BAP é uma das citocininas mais utilizadas na indução de novos brotos e estimula o desenvolvimento dos órgãos da planta (AUER; COHEN, 1993). Assim, acredita-se que a ausência do BAP no meio nutritivo dificultou a multiplicação de abacaxizeiro. Resultados semelhantes referente à ausência de fitor- reguladores foram obtidos por Tamaki et al. (2007).

A taxa de enraizamento, e em todos os tratamentos salinos (Controle - 0; 50; 100 e $150 \mathrm{mM}$ ), na presença e na ausência de fitorreguladores, atingiram $100 \%$ aos 90 dias, sendo antecipada nas plântulas tratadas com ANA e BAP durante a multiplicação (Figura 2 - A e B). Essas plântulas, durante os 30 primeiros dias, já apresentaram formações radiculares. A antecipação na formação das raízes deve-se, provavelmente, à presença da auxina no meio de cultura. O ANA parece ser a auxina mais eficaz para estimular o enraizamento in vitro. Resultados semelhantes foram obtidos por Praxedes et al. (2001), estudando o enraizamento de abacaxizeiro da cultivar Pérola. Atualmente, sabe-se que o enraizamento de brotos é aumentado com apenas $0,05 \mathrm{mg} \mathrm{L}^{-1}$ do ácido naftalenoacético (BORGES et al., 2001).

Em trabalho realizado por Macêdo et al. (2003) com abacaxizeiro da cultivar Pérola, observou-se que a indução de enraizamento em meio MS básico, sem adição de fitorreguladores, provenientes de tratamentos com baixas concentrações de ANA e BAP, foram os que melhor induziram, em média, a formação de raízes. Esse estudo corrobora o sucesso das plântulas de abacaxizeiro MD Gold, do presente trabalho, originárias de tratamentos na ausência de ANA e BAP, que atingiram 100\% de plântulas enraizadas aos 60 dias. O fato é extremamente relevante, pois favorece uma redução no custo das mudas propagadas (DALVESCO et al., 1996).

Segundo Teng (1997), para a micropropagação de abacaxizeiro, o tamanho das plântulas a serem aclimatadas parece ser fundamental para o sucesso da micropropagação, uma vez que brotos inferiores a 2 (dois) centímetros têm baixas taxas de enraizamento. Assim, o tamanho dos brotos originários da multiplicação in vitro, entre 8 e $10 \mathrm{~cm}$, também garantiu a boa taxa de enraizamento. 
TABELA 1 - Valores médios de altura e número de folhas vivas dos brotos de abacaxizeiro da cultivar MD Gold submetidos a diferentes concentrações de $\mathrm{NaCl}$ (Controle - 0; 50; 100 e $150 \mathrm{mM}$ ), cultivados na ausência e na presença de ANA e BAP, durante 90 dias $(0 ; 30 ; 60$ e 90 dias), na fase de multiplicação.

\begin{tabular}{|c|c|c|c|c|c|}
\hline \multirow{3}{*}{ Caracteres } & \multirow{3}{*}{$\mathrm{NaCl}(\mathrm{mM})$} & \multicolumn{4}{|c|}{ Ausência de ANA e BAP } \\
\hline & & \multicolumn{4}{|c|}{ Tempo de exposição (dias) } \\
\hline & & 0 & 30 & 60 & 90 \\
\hline \multirow{4}{*}{$\begin{array}{c}\text { Altura do } \\
\text { Broto }\end{array}$} & 0 & $7,0 \mathrm{~A} * \mathrm{~b}$ & $9,5 \mathrm{Aa}^{* *}$ & $10,0 \mathrm{Aa}$ & $10,5 \mathrm{Aa}$ \\
\hline & 50 & $7,0 \mathrm{Ab}$ & 8,9Aa & $9,2 \mathrm{Aa}$ & $9,5 \mathrm{Aa}$ \\
\hline & 100 & $6,9 \mathrm{Ab}$ & $7,3 \mathrm{Ba}$ & $7,4 \mathrm{Ba}$ & $7,4 \mathrm{Ba}$ \\
\hline & 150 & $6,8 \mathrm{Ab}$ & $7,3 \mathrm{Ba}$ & $7,7 \mathrm{Ba}$ & $7,7 \mathrm{Ba}$ \\
\hline \multirow{4}{*}{$\begin{array}{l}\text { Número de } \\
\text { Folhas }\end{array}$} & 0 & $19,0 \mathrm{Ab}$ & $15,2 \mathrm{Ac}$ & $14,4 \mathrm{Ac}$ & $21,2 \mathrm{Aa}$ \\
\hline & 50 & $16,4 \mathrm{Ba}$ & $13,0 \mathrm{Bb}$ & $11,6 \mathrm{Bc}$ & $16,2 \mathrm{Ba}$ \\
\hline & 100 & $16,6 \mathrm{Ba}$ & $12,4 \mathrm{Bc}$ & $10,2 \mathrm{Bd}$ & $14,2 \mathrm{Cb}$ \\
\hline & 150 & $17,0 \mathrm{Ba}$ & $10,8 \mathrm{Cb}$ & $9,4 \mathrm{Cc}$ & $11,2 \mathrm{Db}$ \\
\hline \multirow{3}{*}{ Caracteres } & \multirow{3}{*}{$\mathrm{NaCl}(\mathrm{mM})$} & \multicolumn{4}{|c|}{ Presença de ANA e BAP } \\
\hline & & \multicolumn{4}{|c|}{ Tempo de exposição (dias) } \\
\hline & & 0 & 30 & 60 & 90 \\
\hline \multirow{4}{*}{$\begin{array}{c}\text { Altura do } \\
\text { Broto }\end{array}$} & 0 & $9,6 \mathrm{Aa}$ & $10,1 \mathrm{Aa}$ & $10,4 \mathrm{Aa}$ & $10,4 \mathrm{Aa}$ \\
\hline & 50 & $9,3 \mathrm{Aa}$ & $10,1 \mathrm{Aa}$ & $10,2 \mathrm{Aa}$ & $10,4 \mathrm{Aa}$ \\
\hline & 100 & $9,7 \mathrm{Aa}$ & $10,3 \mathrm{Aa}$ & $10,3 \mathrm{Aa}$ & $10,3 \mathrm{Aa}$ \\
\hline & 150 & $9,7 \mathrm{Aa}$ & $10,4 \mathrm{Aa}$ & $10,4 \mathrm{Aa}$ & $10,4 \mathrm{Aa}$ \\
\hline \multirow{4}{*}{$\begin{array}{l}\text { Número de } \\
\text { Folhas }\end{array}$} & 0 & $10,0 \mathrm{Ac}$ & $17,0 \mathrm{Ab}$ & $21,4 \mathrm{Aa}$ & $22,0 \mathrm{Aa}$ \\
\hline & 50 & $9,8 \mathrm{Ad}$ & $14,2 \mathrm{Bc}$ & $18,8 \mathrm{Ba}$ & $16,0 \mathrm{Bb}$ \\
\hline & 100 & $12,2 \mathrm{Ac}$ & $15,2 \mathrm{Bb}$ & $19,8 \mathrm{Ba}$ & $15,4 \mathrm{Bb}$ \\
\hline & 150 & $10,4 \mathrm{Ad}$ & $12,4 \mathrm{Cc}$ & $17,6 \mathrm{Ca}$ & $14,0 \mathrm{Cb}$ \\
\hline
\end{tabular}

* Médias acompanhadas da mesma letra em minúsculo, dentro da mesma linha, não diferem a $5 \%$ de probabilidade, pelo teste de Tukey. ** Médias acompanhadas da mesma letra em maiúsculo, dentro da mesma coluna, não diferem a $5 \%$ de probabilidade, pelo teste de Tukey.
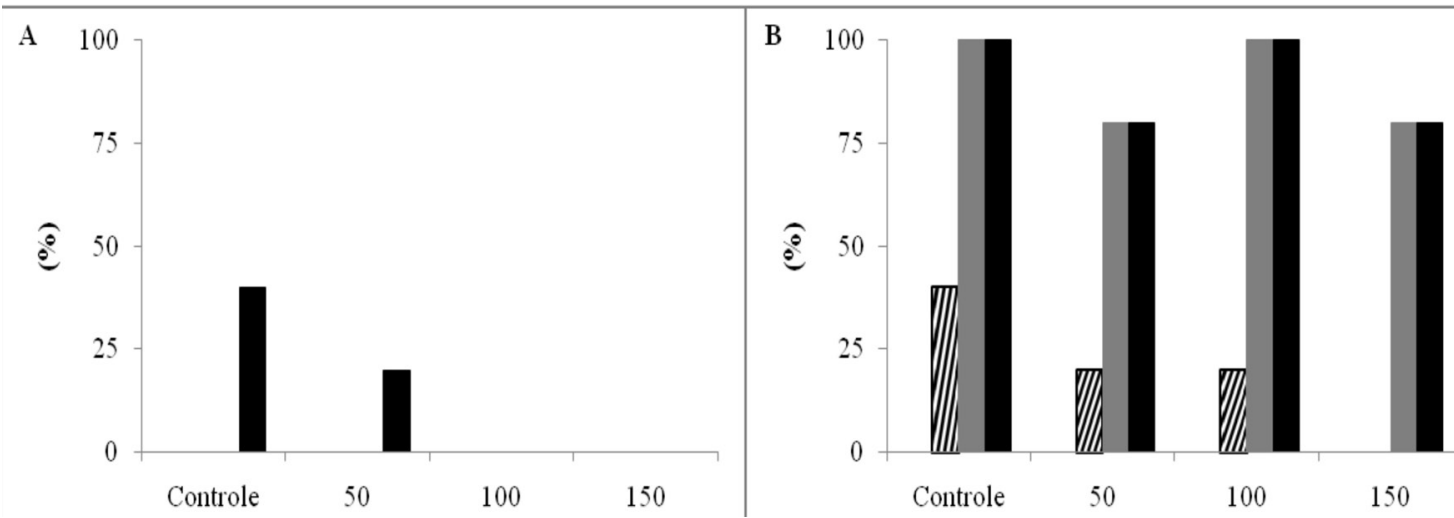

FIGURA 1 - Taxa de brotação em abacaxizeiros da cultivar MD Gold submetidos a diferentes concentrações de $\mathrm{NaCl}$ (Controle - 0; 50; 100 e $150 \mathrm{mM}$ ) cultivados na ausência (A) e na presença (B) de ANA e BAP, durante 90 dias, multiplicação ( $\square 0$ dias, 孟30dias, $\square 60$ dias, 90 dias). 


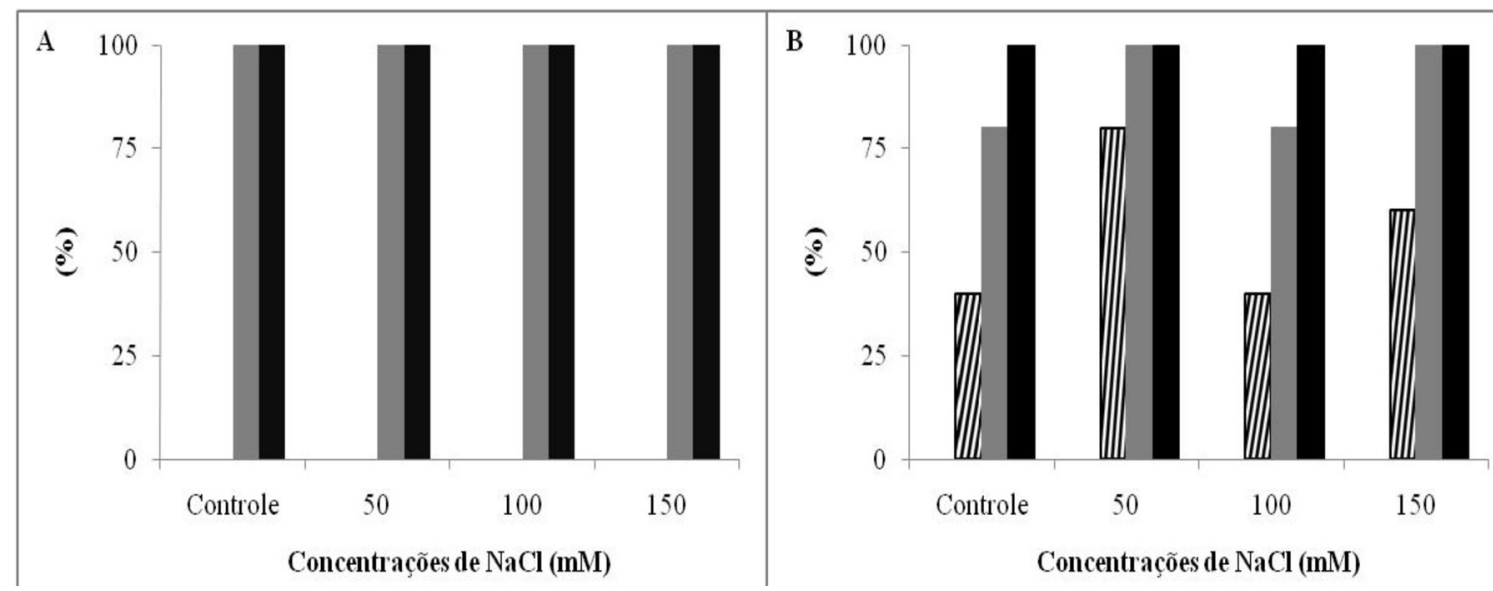

FIGURA 2-Taxa de enraizamento de plântulas de abacaxizeiro da cultivar MD Gold provenientes de diferentes concentrações de $\mathrm{NaCl}$ (Controle - 0; 50;100 e $150 \mathrm{mM}$ ), cultivadas durante a multiplicação na ausência (A) e em presença (B) de ANA e BAP, em meio de enraizamento, durante 90 dias ( $\square 0$ dias, 业 30dias, $\square 60$ dias, $\square 90$ dias).

\section{CONCLUSÕES}

1 - O cultivo in vitro de abacaxizeiro da cultivar MD Gold, em presença de sal, é mais eficiente quando adicionado a fitorreguladores (ANA e BAP), resultando na manutenção do crescimento, expresso pela altura do broto, no aumento do número de folhas, na produção de novas gemas e acelerando o processo de enraizamento. As altas concentrações de $\mathrm{NaCl}$ provocam alterações fisiológicas nos brotos de abacaxizeiro na ausência de ANA e BAP, reduzindo o crescimento e, consequentemente, afetando a multiplicação.

2 - A estratégia para corrigir problemas de salinidade, por altas concentrações de $\mathrm{NaCl}$, em cultivo in vitro de abacaxizeiro, é através do uso de fitorreguladores como ANA e BAP. As adições de tais compostos não alteram o crescimento da planta.

\section{REFERÊNCIAS}

ASCH, F.; DINGKUHN, M.; DORFFING, K. Salinity increases $\mathrm{CO} 2$ assimilation but reduces growth in field grown irrigated rice. Plant Soil, The Hague, v. 218, p. 1-10, 2000.

AUER, C. A.; COHEN, J. D. Identifi cation of a benzyladenine disaccharide conjugate produced during shoot organogenesis in Petunia leaf explants. Plant Physiology, Minneapolis, v. 102, p. 541-545, 1993.
BARROSO, P. A. V.; MOURA, G. E. D. D.; BRITO, L. K. F.; MARTINS, C. P.; MACÊDO, C. E. C.; LOPES, D. B.; ALLOUFA, M. A. I. Efeito do cultivo in vitro na presença de $\mathrm{NaCl}$ em plantas de abacaxizeiro na fase de aclimatação. Revista Brasileira de Engenharia Agrícola e Ambiental, Campina Grande, v. 7, n. 3, p. 473-477, 2003.

BIONOVA 2009. Disponível em: <http://container2.netsite.com.br/bionova/mostra_conteudo. asp? conteudo=14896>. Acesso em: 30 out. 2009.

BORGES, N. S. S.; CORREIA, D.; LIMA, R. N. Multiplicação e enraizamento in vitro de brotos de abacaxi ornamental Ananas porteanus Hort Veitch ex C. Koch. Fortaleza: Embrapa Agroindústria Tropical, 2001. 5 p.

BRILHANTE, J. C. A.; SILVEIRA, J. A. G.; ROCHA, I. M. A.; MORAIS, D. L.; VIEGAS, R. A. Influência do tempo de aclimatação na resposta do cajueiro à salinidade. Revista Brasileira de Engenharia Agrícola e Ambiental, Campina Grande, v. 11, n. 2, p. 173-179, 2007.

BRITO, L. K. F. L.; MOURA, G. E. D. D.; MARTINS, C. P.; ALOUFA, M. A. I.; MACEDO, C. E. C.; LOPES, D. B.; BARROSO, P. A. V. Cultivo in vitro de somaclones de abacaxizeiro na presença de $\mathrm{NaCl}$. Revista Brasileira de Engenharia Agrícola e Ambiental, Campina Grande, v. 11, n. 3, p. 279283, 2007. 
CARMO, G. A.; MEDEIROS, J. F.; TAVARES, J. C.; GHEYI, H. R.; SOUZA, A. M.; PALÁCIO, E. A. Q. Crescimento de bananeiras sob diferentes níveis de salinidade da água de irrigação. Revista Brasileira de Fruticultura, Jaboticabal, v. 25, n. 3, p. 513-518, 2003.

CHAN, Y. K.; COOPENS, E. G.; SANEWSKI, G. M. Breeding and variety improvement. In: BARTHOLOMEW, D. P.; PAULL, R. E.; ROHRBACH, K. G. (Ed.). The pineapple, botany, production and uses. Honolulu: University of Hawaii at Manoa, 2002. p.36-39.

CRUZ, J. L.; PELACANI, C. R.; SOARES FILHO, W. S.; CASTRO NETO, M. T.; COELHO, E. F.; DIAS, A. T.; PAES, R. A. Produção e partição de matéria seca e abertura estomática do limoeiro 'cravo' submetido a estresse salino. Revista Brasileira de Fruticultura, Jaboticabal, v. 25, n. 3, p. 528-531, 2003.

CHAVES, M. M.; FLEXAS, J.; PINHEIRO, C. Photosynthesis under drought and salt stress: regulation mechanisms from whole plant to cell. Annals of Botany, London, v. 103, p. 551-560, 2009.

DALVESCO, L. L.; GUERRA, M. P.; PINTO, A. de A.; NODARI, R. O. Otimização do protocolo regenerativo in vitro para o abacaxizeiro (Ananas comosus (L.) Merril). In: CONGRESSO BRASILEIRO DE FRUTICULTURA, 14., 1996, Londrina. Anais... Londrina: Instituto Agronômico do Paraná, 1996. 561p.

ESTEVES, B. S.;SUZUKI, M. S. Efeito da salinidade sobre as plantas. Oecologia Australis, Rio de Janeiro, v. 12, n. 4, p. 662-679, 2008.

IBGE. Dados de safra de abacaxi no Brasil. 2008. Disponível em: <http://www.sidra.ibge.gov.br/bda/ tabela/protabl1.asp? $\mathrm{c}=1612 \& \mathrm{z}=\mathrm{t} \& \mathrm{o}=11 \& \mathrm{i}=\mathrm{P}>$. Acesso em: 03 nov. 2009.

LUTTS, S.; ALMANSOURI, M.; KINET, J. M. Salinity and water stress have contrasting effects on the relationship between growth and cell viability during and after stress exposure in durum wheat callus. Plant Science, Limerick, v. 167, p. 9-18, 2004.
MACÊDO, C. E. C.; BARROSO, P. A. V.; MOURA, G. E. D. D.; ALLOUFA, A. I. A. Efeito do $\mathrm{NaCl}$ sobre o crescimento e a multiplicação in vitro de bananeira. Revista Brasileira de Fruticultura, Jaboticabal, v. 27, n. 2, p. 194-197, 2005.

MACÊDO, C. E. C.; SILVA, M. G.; NÓBREGA, F. S.; MARTINS, C. P.; BARROSO, P. A. V.; ALLOUFA, M. A. I. Concentrações de ANA e BAP na micropropagação de abacaxizeiro L. Merril (Ananas comosus) e no cultivo hidropônico das plântulas obtidas in vitro. Revista Brasileira de Fruticultura, Jaboticabal, v.25, p.501-504, 2003.

MAIOCHI, R. A.; ROSA, F. A. F.; PESCADOR, R; REBELO, R. A. Efeito do 5,6-metilenodioxindol-3il-formaldeído (3-MIF) no sistema de cultivo in vitro de Nicotiana tabacum L. Revista Brasileira de Biociências, Porto Alegre, v.5, supl. 2, p. 534-536, 2007.

MEDEIROS, D. N.; MACÊDO, C. E. C.; ALLOUFA, M. A. I. Efeito do $\mathrm{NaCl}$ sobre a multiplicação in vitro de abacaxizeiro (Ananas comosus L. Merril). Revista Brasileira de Fruticultura, Jaboticabal, v. 23, n. 1, p. 01-05, 2001.

MORAES, G. A. F.; MENEZES, N. L. Desempenho de sementes de soja sob condições diferentes de potencial osmótico. Ciência Rural, Santa Maria, v. 33, n. 2, 2003.

MURASHIGE, T.; SKOOG, F. A revised medium for rapid growth and bioassays with tobacco tissue cultures. Physiologia Plantarum, Copenhagen, v. 15, p. 473-479, 1962.

MUSCOLO, A.; PANUCCIO, M. R.; SIDARI, M Effects of salinity on growth, carbohydrate metabolism and nutritive properties of kikuyu grass (Pennisetum clandestinum Hoscht). Plant Science, Limerick, v. 164, p. 1.103-1.110, 2003.

PRAXEDES, S. C.; SILVA JÚNIOR, A. F.; FIGUEIREDO, F. L. B.; FIGUEIREDO, M. L.; CÂMARA, F. A. A.; OLIVEIRA, O. F. Estiolamento in vitro do abacaxizeiro Pérola em presença de ANA e AIA. Caatinga, Mossoró, v. 14, p. 13-15, 2001.

TAMAKI, V.; MERCIER, H.; NIEVOLA, C. C. Cultivo in vitro de clones de Ananas comosus (L.) Merril. cultivar 'Smooth Cayenne' em diferentes concentrações de macronutrientes. Hoehnea, São Paulo, v.34, p. 69-73, 2007. 
TENG, W. L. An alternative propagation method of Ananas through nodule culture. Plant Cell Reports, Heidelberg, v. 16, p. 454-457, 1997.

VIEIRA, C. F.; GOMES, I. A.; BRITO, L. K. F. L.; MACÊDO, C. E. C.; CARVALHO, A. C. P. P. Cultivo in vitro de brotos de abacaxizeiro (ananas comosus var. comosus) cv. md gold em presença de $\mathrm{NaCl}$. In: CONGRESSO BRASILEIRO DE FRUTICULTURA,54., ANNUAL MEETING OF THE INTERAMERICAN SOCIETY FOR TROPICAL HORTICULTURE,10., 2008, Vitória. Anais... 1 CD-ROM.
XIONG, L.; ZHU, J. Molecular and genetic aspects of plant responses to osmotic stress. Plant, Cell and Environment, Nottingham, v. 25, n. 2, p. 131-139, 2001.

ZHU, J. K. Plant salt tolerance. Trends in Plant Science, Oxford, v. 6, p. 56-71, 2001. 